\title{
The Use of High Strain Rate Testing to the Study of Turbine Missile Impact
}

\author{
J. Buchar, M. Lazar*, S. Rolc** and J. Hrebícek*** \\ Mendel University of Agriculture and Forestry, Zemedelská 1, 61300 Brno, Czech Republic \\ * Military Research Institute, Záhorie, 90524 Senica, Slovak Republic \\ ** Military Research Institute, Rybkova2a, P.O.B. 547, 60200 Brno, Czech Republic \\ *** Masaryk University, Buresova, 60000 Brno. Czech Republic
}

\begin{abstract}
A study of the interaction of turbine blades with the steel plate has been conducted. Experiments simulating this event have been numerically simulated using DYNA 3D code. This mathematical modelling needs reliable constitutive relations describing the material behaviour. These constitutive equations have been suggested on the results of material testing by the Hopkinson Split Bar Technique. Their validity has been further tested using of the Taylor impact test. It has been found that the computed values of the projectile residual velocities well agree with the experimental data for different impact velocities and for the turbine fragments of different shapes.
\end{abstract}

Résumé : On étudie l'interaction d'une aube de turbine avec une plaque d'acier. Les expériences effectuées ont été simulées par le code DYNA 3D. Cette simulation exige des relations constitutives fiables décrivant lé comportement des matériaux. Ces équations constitutives ont été obtenues par la techniqué de la harre d'Hopkinson. La validité des résultats a été ensuite vérifiée par le test de Taylor. La valeur de la vitesse résiduelle calculée du projectile est en bon accord avec les données obtenues par l'expérience dans tout le domaine des vitesses d'incidence et pour des tragments d'aube de turbine de diflërentes iormes.

\section{INTRODUCTION.}

The impact of the turbine blade or its fragments against protective steel plate has been considered in the past by nuclear power plant designers to provide adequate protection to specific plant components. The fragments of blade can be irregularly shaped and can posses ejection velocities over $300 \mathrm{~m} / \mathrm{s}$, thus representing a potential cause of damage to the structural parts.In the past, the empirical formulations have been used. The most simple solution of this problem consists in the use of some empirical relations or analytical procedures [1]. The empirical formulations have been developed for the relatively small projectiles. The use of the analytical models is also very complicated owing to the irregular shape of the fan blades. The exact solution thus needs the use of some numerical codes like DYNA, AUTODYN etc. The use of these codes is conditioned by the knowledge of the reliable constitutive equations of the material behaviour. There exists a number of different types of constitutive equation with increasing complexity and number of empirical constants to be evaluated [2,3]. From a designers point of view a constitutive equation must be chosen based on the available data.

In the present paper we deal with the experimental procedure leading to the design of the constitutive equation which can accurately describe the material behaviour during the impact. The experiments have been performed when turbine blades were fired against steel plates. This event is numerically simulated using DYNA 3D code. The experimentally determined and computed values of the residual velocities of the turbine blades are compared. 


\section{EXPERIMENTS.}

In Fig. 1 the photos of the turbine blades are presented. These blades were launched from the tank cannon (calibre $100 \mathrm{~mm}$ ) using a special sabot technology. The velocity of this projectile before the impact have been measured by the network of wires.

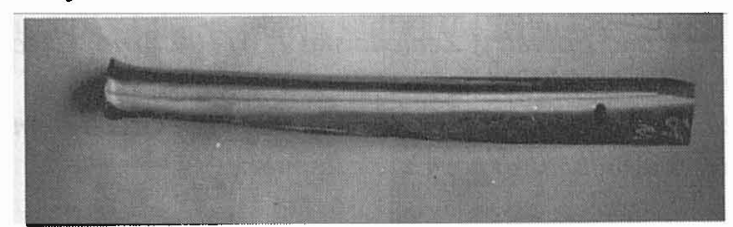

Fig.1. The turbine blade missile. (length $-1 \mathrm{~m}$, weight $6 \mathrm{~kg}$ ).

The same technique bas been used for the measurement of the residual velocity of the blade after perforation of the steel plate $(2 \times 2 \times 0.025 \mathrm{~m})$. The arrangement guarantees a normal incidence of the blade. The kinematics evaluation of the turbine blade movement suggests that the impact velocities may lie between 200 and $400 \mathrm{~m} / \mathrm{s}$. In order to achieve these velocities we performed a series of experiments with the projectile in form of a rod of the same weight as the turbine blades. The dependence of the impact velocity on the weight of the powder was determined. The real impact velocities of the turbine blade are different from this prediction owing to the different exterior ballistics of the turbine blade in comparison with the rod. The measured impact velocities of blades were 248 and $403 \mathrm{~m} / \mathrm{s}$. The steel plates were perforated. The residual velocities were 187 and $281.7 \mathrm{~m} / \mathrm{s}$. The extent of the steel plate damage has been also evaluated. The second series of the experiments has been focused on the determination of the constitutive equations. The tensile tests of the materials (i.e. material of the steel plate and turbine blade) have been performed. The dependence of the stress on the plastic strain can be fitted by the equation

$$
\sigma=\sigma_{s}+C \varepsilon^{n}
$$

where $\sigma_{S}$ is the static yield point and $C$ and $p$ are material parameters. The parameters $\sigma_{S}, C$ and $n$ are given in Table 1.

The strain rate sensitivity of the given materials has been tested using of the Hopkinson Split Pressure Bar (HSPB) Technique. In Fig. 2 the dependencies of the yield point and the flow stress on the strain rate are displayed.

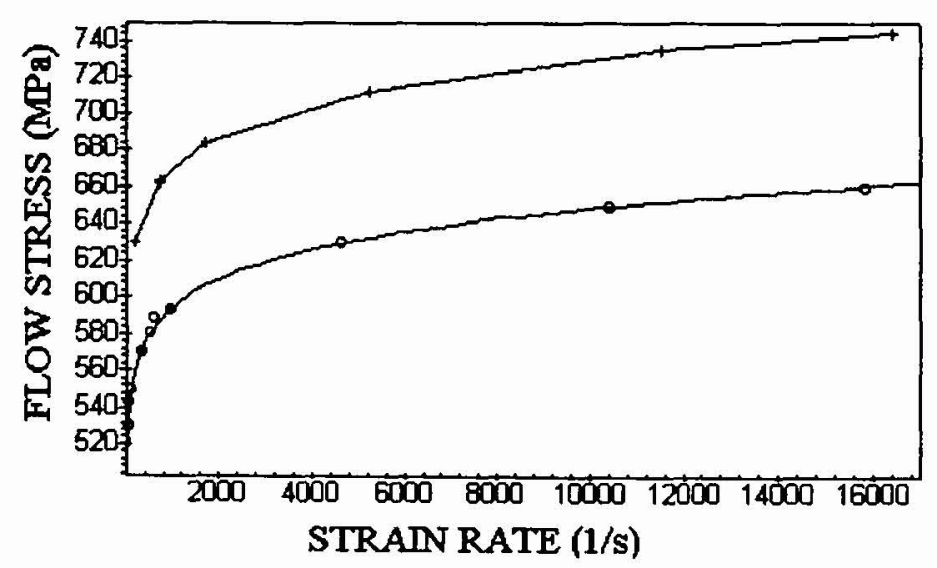

Fig.2. The strain rate dependence of the yield point (circles) and the flow stress (cross, plastic strain is 0.01 ) for the material of the protective plate. 
It has been found that the influence of the strain rate can be described by the Cowper - Symonds equation when the static yield point and/or the flow stress is multiplied by the factor

$$
1+\left(\frac{\frac{\partial}{\partial t} \varepsilon}{D}\right)^{\left(\frac{1}{p}\right)}
$$

The parameters $D$ and $p$ can be determined from the HSPB test. In order to verify these parameters we performed the Taylor test when the specimens $25 \mathrm{~mm}$ in length and $5 \mathrm{~mm}$ in diameter were used. These experiments were simulated using of DYNA 3D code where the constitutive equation

$$
\sigma=\left(\sigma_{s}+C \varepsilon^{n}\right)\left(1+\left(\frac{\frac{\partial}{\partial t} \varepsilon}{D}\right)^{\left(\frac{1}{p}\right)}\right)
$$

was used. The computed and measured specimen profiles were compared. This procedure enables to determine the optimum values of parameters in Eq.(3). The parameters $\mathrm{D}$ and $\mathrm{p}$ are also given in Table 1.

Table 1. Parameters of the Eq.(3)

\begin{tabular}{|c|c|c|c|c|c|}
\hline Material & $\sigma_{\boldsymbol{s}}(\mathrm{MPa})$ & $p(-)$ & $D\left(\mathrm{~s}^{-1}\right)$ & $C(\mathrm{MPa})$ & $n(-)$ \\
\hline Steel plate & 270 & 14.9 & 65.6 & 142 & 0.31 \\
\hline Turbine blade & 770 & 18.0 & 1603.0 & 158 & 0.26 \\
\hline
\end{tabular}

In the next step we focused on the evaluation of the fracture strain $d$. There are many models which predicts the dependence of this strain on the stress, strain rate and temperatures [4]. From our experiments performed with the rod projectiles we determined that the fracture strain has a value of 0.8 . This value led to the best agreement between measured and computed values of the residual projectiles velocities.

\section{NUMERICAL SIMULATIONS.}

The finite element approximation of the experiments described in the previous chapter is given in Fig. 3 . The main results of the numerical computation is the velocity of the turbine blade during its perforation of the steel plate. After the perforation of the plate the turbine blade exhibits all three components of the velocity. The time dependence of the $x$-component of the velocity is shown in Fig. 4 . The value of the residual velocity ( $z$ - component) is $281.85 \mathrm{~m} / \mathrm{s}$ which nearly exactly agrees with experimental one. For the second experiment we obtained the residual velocity of the turbine blade as $179.35 \mathrm{~m} / \mathrm{s}$. This value is slightly lower than that given by the experiment $(187 \mathrm{~m} / \mathrm{s})$.

In the next step we performed a numerical simulation of the turbine blade impact at the oblique incidence where the following components of the impact velocity are given : $v_{x}=0 \mathrm{~m} / \mathrm{s}, v_{y}=-482.5$ $\mathrm{m} / \mathrm{s}, v_{z}=-482.5 \mathrm{~m} / \mathrm{s}$. Results are displayed in Figs. 5 and 6. It was found that during the plate perforation no erosion of the turbine blade occurred. The residual projectile velocity remains unchanged even if we assume a rotation of the turbine blade around the $x$ - axes. 


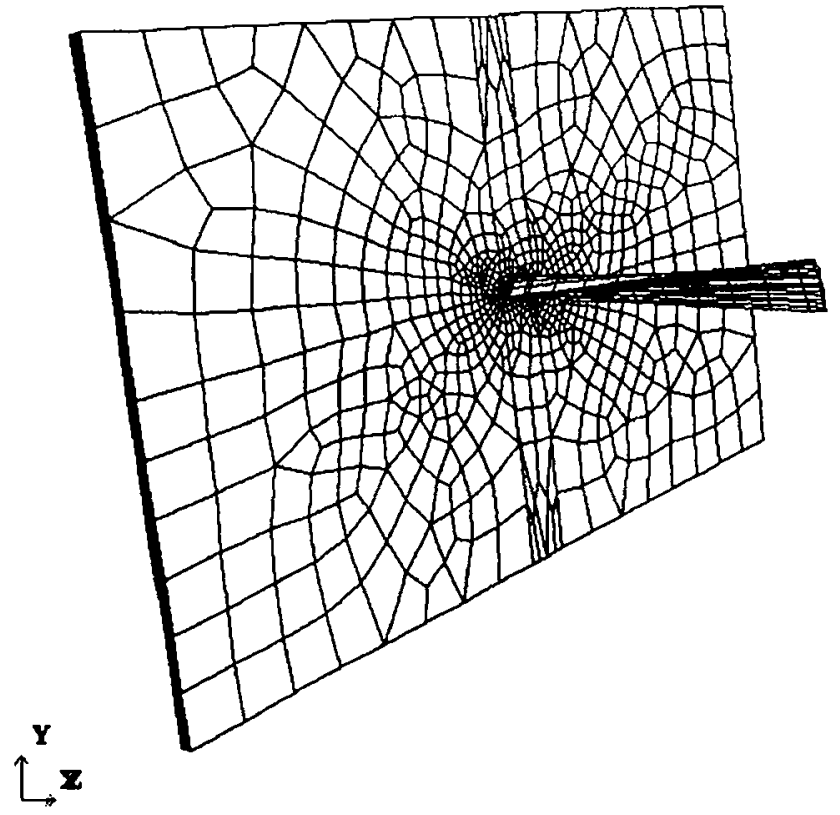

Fig.3. Typical finite mesh for the normal incidence.

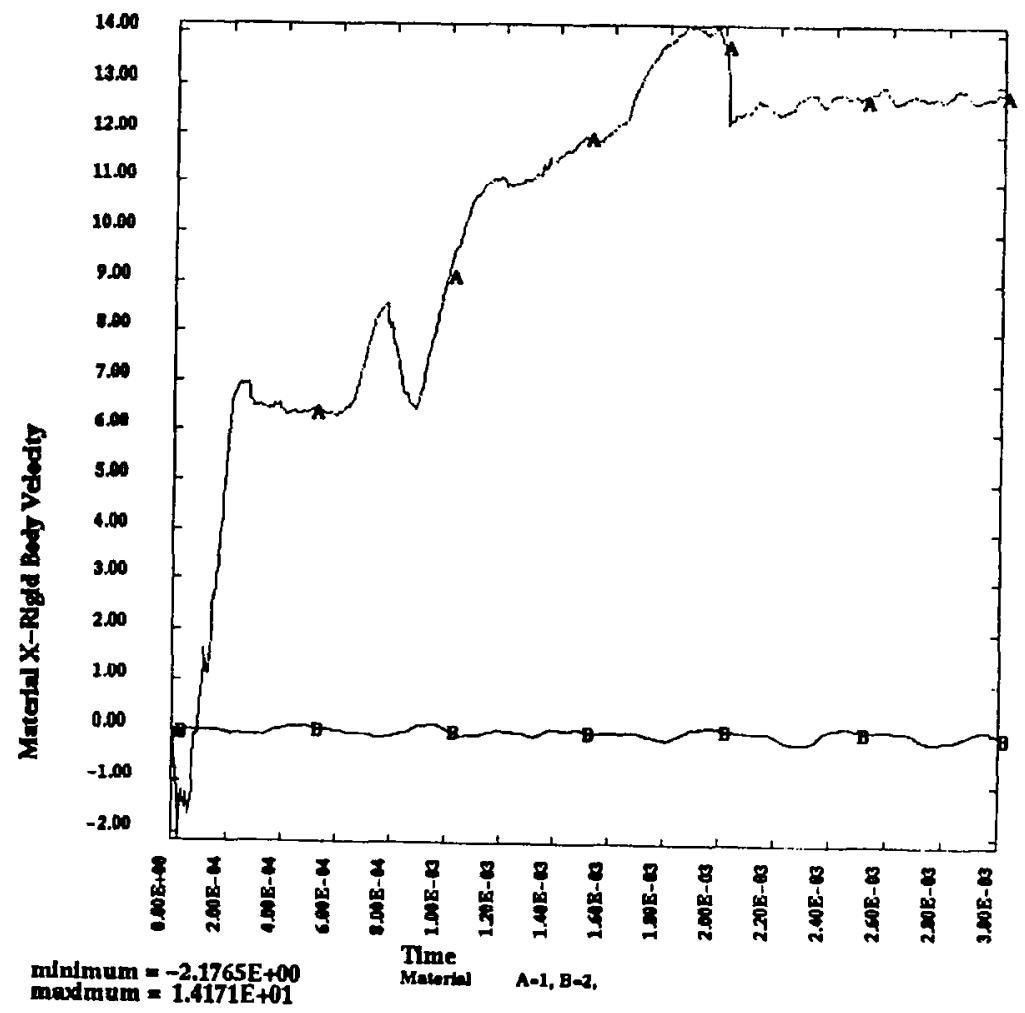

Fig.4. Time dependence of the x-component of the velocity (A - blade, B-plate). 


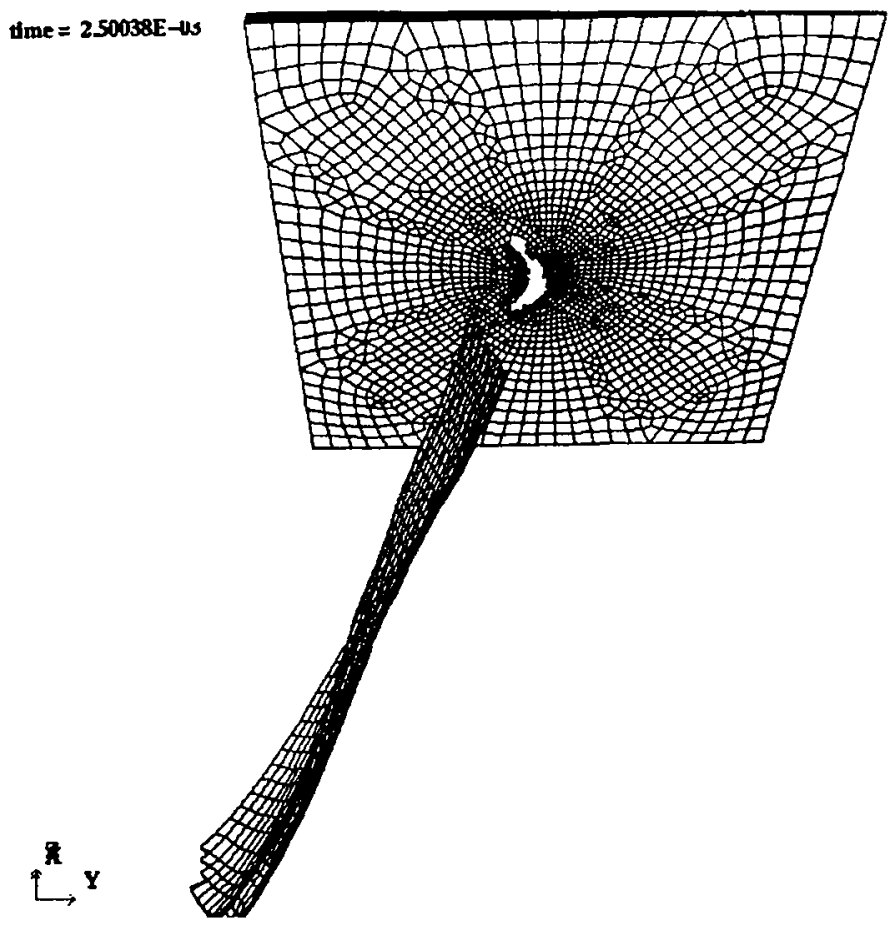

Fig.5. Perforation of the protective plate by the turbine blade (Oblique impact)

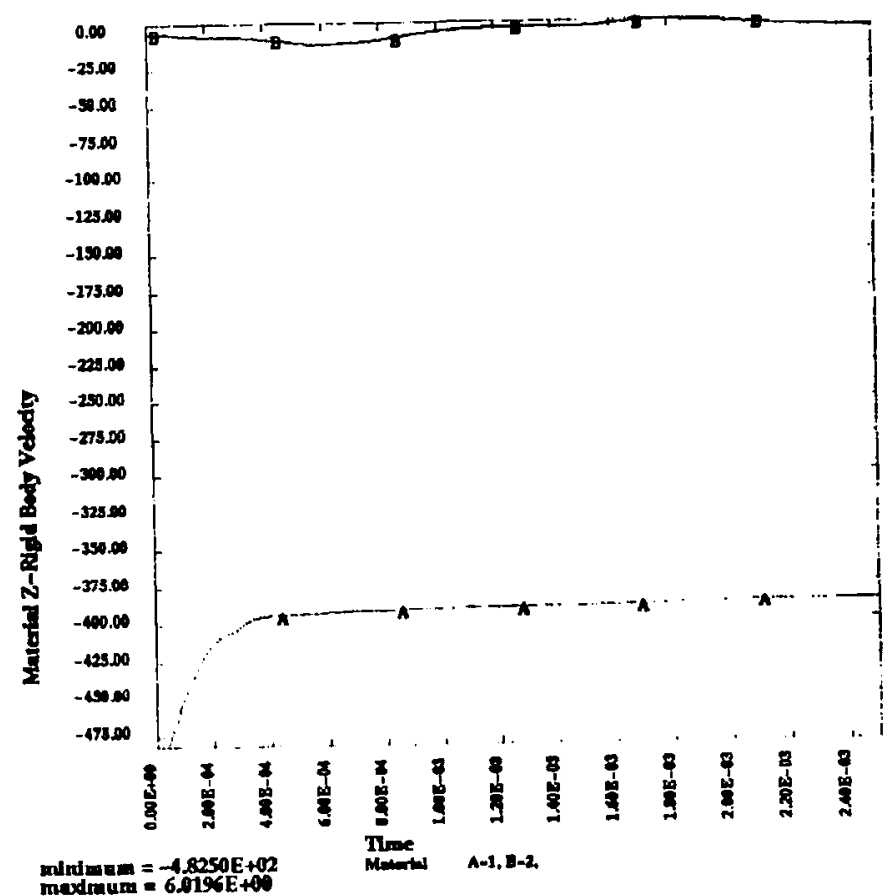

Fig.6. Time dependence of the z-component of the velocity (A - blade , B- plate, oblique impact). 


\section{CONCLUSION}

The results of this paper show that the material behaviour during the impact of the body of a irregular shape can be described by a simple constitution equation which can be found using of a nearly standard material tests combined with a numerical simulations. By this way we are able to design a protective structures taking into account a variety different conditions ( different shape of the impacted body, obliquity of the impact, different impact velocities etc.) without necessity of performing of many expensive experiments.

\section{Acknowledgement.}

This work was supported by the Czech Grant Agency under contract No 106/94/0567.

\section{References.}

[1] Corbett G.G., Reid S.R and Johnson W., Int. J.Impact Engng 18, (1996) 141-230.

[2] Johnson G.R., Cook W.H., Eng. Fracture Mechanics 21 (1985) 31-48.

[3] Zerilli F.J., Armstrong R.W., Journal of Applied Physics 61(5) (1987) 1816 - 1825.

[4] Zukas J.A., High Velocity Impact Dynamics. John Wiley \& Sons,Inc. New York 1990. 